\title{
CARACTERIZAÇÃO DE ESTRESSE HÍDRICO DE DUAS LINHAGENS DE MILHO (Zea mays L.) COM SONDAS DE FLUXO DE SEIVA
}

\author{
REINALDO LÚCIO GOMIDE ${ }^{1}$, FREDERICO OZANAN MACHADO DURÃES ${ }^{1}$, MAURO KOJ \\ KOBAYASHI ${ }^{2}$, ROGÉRIO ALESSANDRO FARIA MACHADO ${ }^{3}$
}

${ }^{1}$ Pesquisadores da Embrapa Milho e Sorgo. Rodovia MG 424, Km 45, Caixa Postal 151, 35701-970 Sete Lagoas, MG. E-mail: gomide@cnpms.embrapa.br (autor para correspondência).

2 Prof. de Agronomia da UNIMONTES. Rua Reinaldo Viana, 2630, 39440-000 Janaúba, MG

${ }^{3}$ Prof. de Agronomia da UNEMAT. Av. Tancredo Neves, 1095, 78200-000 Cáceres, MT.

Revista Brasileira de Milho e Sorgo, v.4, n.3, p.344-354, 2005

RESUMO - A reposição parcial da necessidade hídrica das plantas e a seleção de genótipos melhor adaptados às condições limitantes de água podem contribuir para o aumento da disponibilidade de água na agricultura. Embora os efeitos de estresses hídricos sobre o desenvolvimento das culturas sejam conhecidos, existem poucas metodologias confiáveis usadas para as suas caracterizações baseadas em parâmetros diretamente relacionados com as plantas, visando manter bons níveis de produtividade e aumentar a tolerância à deficiência hídrica, principalmente devido às dificuldades de controle ambiental do fator hídrico. Com base nesse enfoque, o presente trabalho objetivou caracterizar o estresse hídrico de duas linhagens de milho (Zea Mays L.) por meio de monitoramento automático de fluxo de seiva (F), com sondas de balanço de energia instaladas em segmentos de caules de plantas. As sondas são compostas de resistência elétrica de aquecimento (jaqueta térmica) e sensores de registro de fluxo de calor e temperatura. A jaqueta térmica forneceu uma taxa constante de calor ao segmento do caule. Termopares de cobre-constantan foram usados como sensores, para detectar as perdas de calor da superfície da jaqueta térmica para o ar ao redor do caule e as diferenças de temperatura no segmento do caule estudado. O sistema automático de aquisição de dados foi composto de um datalogger, sensores, um computador portátil, um painel solar e baterias recarregáveis. Um programa foi usado para fazer leituras nas sondas e cálculos das taxas de fluxo de seiva. Uma equação, expressando o índice de estresse hídrico de plantas (IEHP) e envolvendo termos das taxas de F medidas sob duas condições de regime hídrico (não estressado e estressado), foi usada na caracterização do estresse hídrico. Os resultados indicaram que as sondas mostraramse sensíveis para detectar variação de fluxo de seiva e o IEHP mostrou-se uma metodologia adequada para caracterização hídrica das duas linhagens de milho investigadas; a área foliar total das duas linhagens estudadas foi reduzida pela condição do estresse hídrico; a linhagem de milho L 1170 apresentou menores valores de fluxo de seiva e mostrou-se mais sensível (maiores valores) ao IEHP estudado; a linhagem de milho L 13.1.2 apresentou maiores valores de fluxo de seiva e mostrou-se mais tolerante (menores valores) ao IEHP.

Palavras-chave: transpiração, balanço de energia no caule, termopares, fluxo de calor e temperatura, automação. 


\title{
WATER STRESS CHARACTERIZATION OF TWO MAIZE (Zea mays L.) INBRED LINES WITH SAP FLOW PROBES
}

\begin{abstract}
The partial replacement of the plants water requirements and the selection of better genotypes adapted to the water shortage conditions can contribute to the increase of water availability in the agriculture. Although the effects of water stresses on the crop development are known, few reliable methodologies used for its characterizations based on parameters directly related to the plants exist, aiming to maintain good productivity levels and to increase the tolerance to water deficiency, mainly due to the difficulties of environmental control of water factor. Based on this focus, the objective of this work was to characterize the water stress of two maize (Zea mays L.) inbred lines by means of automatic sap flow (F) measurements with energy balance probes, installed on segments of plants stems. The probes are composed of heating electric resistance (thermal jacket) and registering sensors of heat and temperature flow. The thermal jacket supplied a constant rate of heat to the stem segment. Thermocouples of copper-constantan were used as sensors to detect the losses of heat from the thermal jacket to the air surrounding the stem and the temperature differences in the stem segment studied. The automatic acquisition data system involved a datalogger, sensors, a portable computer, a solar panel and rechargeable batteries. A program was used for readings in the probes sensors and calculations of the sap flow rates. An equation, expressing the plants water stress index (PWSI) and involving terms of the measured $\mathrm{F}$ rates under two water regime conditions (non stressed and stressed), was used in the water stress characterization. The results indicated that the probes were sensible to detect variation of sap flow and the PWSI was an appropriate methodology for water stress characterization of the two maize inbred lines investigated; the total leaf area of the two studied inbred lines was reduced by the water stress condition; the maize inbred line L 1170 presented smaller values of sap flow and was more sensible (larger values) to the PWSI studied, the maize inbred line L 13.1.2 presented larger values of sap flow and was more tolerant to PWSI (smaller values).
\end{abstract}

Keywords: transpiration, energy balance in the stem, termocouples, flow of heat and temperature, automation.

As respostas de plantas aos estresses hídricos estão associadas com o seu conteúdo interno de água. Embora sejam conhecidos os efeitos desses estresses, são poucos os resultados práticos significativos. Esforços direcionados para a seleção visando aumentar a tolerância à deficiência hídrica em genótipos de milho tropical têm sido realizados, e a utilização desses genótipos visa aumentar a produtividade em condições de difícil controle ambiental do fator hídrico. A adaptação de plantas a ambientes adversos ou a condições de fatores ambientais subótimos envolve a adaptação a estresses múltiplos, com interações diretas e indiretas. Assim, torna-se de grande importância a identificação e a caracterização de genótipos, bem como os estudos sobre a interação e a sobreposição de mecanismos, tanto do ponto de vista fisiológico quanto bioquímico e molecular (Durães et al. 2002; Hale \& Orcutt, 1987). A elucidação desses mecanismos facilitará, por certo, o processo de geração de novos materiais genéticos, além de contribuir para o desenvolvimento de técnicas de seleção que podem reduzir o tempo e o 
trabalho para avaliação de fontes genéticas de tolerância a estresses abióticos de estresse hídrico.

Os recursos hídricos estão se tornando cada vez mais escassos, requerendo estudos criteriosos voltados para a racionalização e o uso mais eficiente da água. A medição da necessidade e do défice hídrico de culturas envolve parâmetros ligados ao contínuo solo-planta-atmosfera. Caracterizar o estresse hídrico tem-se tornado um tema importante para programar a irrigação e selecionar genótipos de plantas mais resistentes ao défice hídrico, desde que se obtenham métodos eficientes de quantificar esse défice e seu efeito no crescimento das plantas (Hale \& Orcutt, 1987; Merva, 1996). Medidas diretas de parâmetros de plantas, associadas com algumas medidas climáticas, em nível de superfície, tais como temperatura e umidade relativa do ar, défice de pressão de vapor d'água do ar, radiação solar e velocidade do vento, podem ser a alternativa para um melhor conhecimento da deficiência hídrica das culturas, auxiliando a seleção de genótipos melhor adaptados às condições limitantes de água e o controle de reposição parcial da necessidade hídrica das culturas, onde seria previsto o manejo de irrigação com estresse hídrico.

A taxa de transpiração (T) tem um grande efeito no estatus hídrico das plantas, em diversos processos metabólicos e no crescimento e desenvolvimento das plantas (Hale \& Orcutt, 1987; Merva, 1996). As condições ambientais (solo, água e atmosfera) e a constituição genética das espécies afetam diretamente a taxa de transpiração das plantas (Merva, 1996). O estresse hídrico ocorre sempre quando a água disponível no solo reduzir a níveis que diminuem a absorção normal de água pelo sistema radicular das plantas e quando as condições atmosféricas forem favoráveis à perda contínua de vapor d'água por transpiração das plantas e evaporação direta da superfície do solo. Essa situação é verificada quando há supressão parcial ou total de aplicação de água às plantas, devido à distribuição irregular das precipitações pluviais e ao manejo inadequado da água de irrigação.

A determinação da taxa de transpiração das plantas pode ser realizada com medições automáticas de fluxo de circulação de seiva nos caules (sistema vascular: conjunto de vasos do xilema), por meio de métodos denominados de termoelétricos, que se baseiam na condição de estado de equilíbrio térmico verificado após a aplicação do calor na forma de um pulso (Cohen et al., 1981; Edwards \& Warwick, 1984; Gomide et al., 1992), de um aquecimento contínuo (Cermak et al., 1976) ou de um balanço de energia (Pickard, 1973; Sakuratani, 1981, 1982 e 1984). Tais métodos requerem o conhecimento das propriedades térmicas do tecido vegetal do caule, isto é, calor específico, condutividade térmica e densidade. Neste trabalho, foram utilizados todos os procedimentos e recomendações do método termoelétrico de balanço de energia nos caules das plantas proposto por Sakuratani (1984). A metodologia baseia-se em uma quantidade de calor, Q (W), que é suprida continuamente, a uma taxa constante, aos segmentos de caules de plantas previamente selecionadas. Nesse caso, o balanço de energia em condições de equilíbrio térmico é fornecido pela equação $\mathrm{Q}=$ $\mathrm{Q}_{\mathrm{f}}+\mathrm{q}_{\mathrm{u}}+\mathrm{q}_{\mathrm{d}}+\mathrm{q}_{\mathrm{s}}$ em que, $\mathrm{Q}_{\mathrm{f}}(\mathrm{W})$ é a energia dissipada devido ao fluxo de massa de seiva (água), $q_{u}$ e $q_{d}($ ambos em W) representam a energia dissipada abaixo e acima do volume de controle (segmento de caule) devido à condução térmica ao longo do caule da planta e $\mathrm{q}_{\mathrm{s}}(\mathrm{W})$ é a energia da superfície do volume de controle dissipada para o ar ao redor do caule por meio de convecção.

Tendo em vista a utilização e o desenvolvimento de técnicas de seleção que podem redu- 
zir o tempo e o trabalho para avaliação de fontes genéticas de tolerância a estresses abióticos de estresse hídrico, o presente trabalho teve o propósito de caracterizar o estresse hídrico de duas linhagens de milho (Zea mays L.) por meio de monitoramento automático de fluxo de seiva, ou seja, da taxa de transpiração com sondas de balanço de energia instaladas em segmentos de caules de plantas. Uma equação, denominada de índice de estresse hídrico de plantas (IEHP), foi usada na caracterização do estresse hídrico. As taxas de fluxo de seiva (F) medidas sob duas condições de regime hídrico (não estressado e estressado) foram os termos usados nesta equação.

\section{Material e Métodos}

Os estudos foram realizados em condições de casa-de-vegetação, na Embrapa Milho e Sorgo, em Sete Lagoas, MG, em oito vasos de $20 \mathrm{Kg}$. O solo usado como substrato foi retirado da camada 0,0 a $0,20 \mathrm{~m}$ do perfil e classificado como Latossolo Vermelho-Amarelo álico, textura média, fase cerrado. Os potenciais matriciais $\left(\Psi_{\mathrm{ms}}\right)$ desse solo de $-0,015 \mathrm{MPa}$ e $1,50 \mathrm{MPa}$ forneceram conteúdos de água $\left(\theta_{\mathrm{s}}\right)$ de $34,8 \%$ e $26,4 \%$ ( $\%$ com base em volume), que corresponderam à capacidade de campo e ao ponto de murcha permanente $\left(\theta_{\mathrm{cc}}\right.$ e $\left.\theta_{\mathrm{pmp}}\right)$, respectivamente. Antes da semeadura, cada vaso recebeu adubação de $10 \mathrm{~g}$ de sulfato de amônio, $27 \mathrm{~g}$ de superfosfato simples, $5 \mathrm{~g}$ de cloreto de potássio, $20 \mathrm{~g}$ de sulfato de magnésio e $0,6 \mathrm{~g}$ de sulfato de zinco, com base na análise química do laboratório de fertilidade do solo da Embrapa Milho e Sorgo. A adubação de cobertura constou de $2 \mathrm{~g}$ de sulfato de amônio, aplicado em cada vaso, semanalmente, a partir do estádio V6 até o florescimento.

As duas linhagens de milho estudadas, $L$ 1170 e L 13.1.2, foram semeadas manualmente em 14/02/2001, com oito sementes por vaso e, aos quinze dias após a emergência, foi realizado um desbaste, deixando-se 3 plantas por vaso. Todas as plantas foram mantidas com um regime hídrico adequado, com o conteúdo de água no solo próximo da $\theta_{\text {cc }}$ (não estressado - NE) até 13/ 04/2001, 58 dias após a semeadura (DAS), período correspondente ao início do florescimento. Depois dessa data, quatro vasos de cada uma dessas linhagens foram mantidos sob duas condições de regime hídrico, isto é, um não estressado (NE) e outro estressado (ES), com conteúdos de água no solo $\left(\theta_{\mathrm{s}}\right)$ próximos aos valores de $34,8 \%$ e $29,0 \%$, que corresponderam aos potenciais matriciais $\left(\Psi_{\mathrm{ms}}\right)$ de $-0,015 \mathrm{MPa}$ e -0,3 MPa, respectivamente. $\mathrm{O}$ controle do conteúdo de água no solo foi realizado por meio de pesagens, empregando-se uma balança eletrônica digital com capacidade de $32 \mathrm{~kg}$ e resolução de $0,005 \mathrm{~kg}$, que funcionou como minilisímetro. Os tratos culturais foram executados sempre que se fizeram necessários. No final das medições do fluxo de seiva, foram colhidas todas as folhas de cada uma das três plantas de cada vaso e de cada regime hídrico, para determinação da área foliar total, com um integrador de área foliar eletrônico da LI-COR, modelo LI-3100.

O sistema de medição automática de fluxo de seiva consistiu de oito sondas do tipo "Dynagage", modelo SGB 19, fabricadas pela Dynamax Inc. (Bavel et al., 1994) e baseou-se no método de balanço de energia nos caules das plantas (Sakuratani, 1984), conforme mostra a Figura 1. Em cada uma dessas sondas, a resistência elétrica de aquecimento (jaqueta térmica) e os sensores de medição de fluxo de calor e de temperatura encontram-se montados em um único bloco (Figura 1a). A jaqueta térmica forneceu a taxa constante de calor ao segmento do caule. Os sensores de fluxo de calor e temperatura con-

Revista Brasileira de Milho e Sorgo, v.4, n.3, p.344-354, 2005 
tidos nas sondas foram termopares de cobreconstantan, usados para detectar as perdas de calor da superfície da jaqueta térmica para o ar ao redor do caule e as diferenças de temperatura no caule, respectivamente. As sondas são flexíveis e ajustáveis aos caules das plantas e não provocam nenhum distúrbio nos segmentos de caules selecionados para instalação.

No período correspondente ao início da fase de florescimento, isto é, aos 58 dias após a semeadura (DAS), as sondas foram instaladas em segmentos de caules de quatro plantas das linhagens L 1170 e L 13.1.2, por meio de suas aberturas radiais, no período entre 7 e 8 horas da manhã, visando aproveitar o momento em que os diâmetros dos caules das plantas estavam ainda reduzidos e, com isso, assegurar o bom ajuste das sondas com as superfícies dos caules. Os segmentos de caules selecionados foram limpos e, em seguida, foi espalhada uma camada fina de silicone, para garantir selamento e contato das jaquetas térmicas das sondas com as superfícies dos caules e, também, vedação do local, evitando infecção de fungos e ataque de pragas. Em seguida, as sondas foram revestidas com folhas de alumínio, para funcionar como abrigo e refletir a radiação incidente. Anéis isolantes na cor branca foram finalmente instalados no topo e abaixo das sondas, com a finalidade de proteção e isolamento dos segmentos de caules selecionados para as medições (Figura 1a).

O sistema automático de aquisição de dados envolveu um datalogger, as oito sondas, um computador portátil e um painel solar (Figura 1). A fonte de energia que alimentou o sistema foi proveniente do painel solar e baterias recarregáveis. Um software gerenciou todo o processo de aquisição automática de dados e cálculos das taxas de fluxo de seiva.
O fluxo de seiva no caule da planta foi determinado pela seguinte equação (Sakuratani, 1984):

$$
F=\frac{Q-k A \frac{\left(T_{u}-T_{u}{ }^{\prime}\right)+\left(T_{d}-T_{d}{ }^{\prime}\right)}{\Delta x}-K E}{c\left(T_{d}-T_{u}\right)} \times 3600
$$

em que: F é o fluxo de seiva $\left(\mathrm{g} \mathrm{h}^{-1}\right)$, Q é a quantidade de calor suprida ao segmento de caule (W), $T_{u}$ e $T_{d}$ são as temperaturas do caule nos limites inferior e superior do segmento aquecido, respectivamente $\left({ }^{\circ} \mathrm{C}\right), \mathrm{T}_{\mathrm{u}}$ ' é a temperatura do caule a uma distância $\Delta x(\mathrm{~m})$ abaixo do ponto de medida de $\mathrm{T}_{u}\left({ }^{\circ} \mathrm{C}\right), \mathrm{T}_{\mathrm{d}}$ 'é a temperatura do caule a uma distância (m) acima do ponto de medida de $\mathrm{T}_{\mathrm{d}}\left({ }^{\circ} \mathrm{C}\right)$, K é uma constante $\left(\mathrm{W} \mathrm{mV}^{-1}\right)$, E é a força eletromotriz (v) do elemento sensor de fluxo de calor preso ao segmento aquecido, $\mathrm{k}$ é a condutividade térmica do caule $\left(\mathrm{Wm}^{-1}{ }^{\circ} \mathrm{C}^{-1}\right)$, A é a área da seção transversal do segmento de caule aquecido $\left(\mathrm{m}^{2}\right)$ e c é o calor específico da seiva ( $\mathrm{J}$ $\left.\mathrm{g}^{-1}{ }^{\circ} \mathrm{C}^{-1}\right)$. Os parâmetros $\mathrm{T}_{u}, \mathrm{~T}_{\mathrm{d}}, \mathrm{T}_{u}$, e $\mathrm{T}_{\mathrm{d}}$ ' foram obtidos com os sensores de fluxo de temperatura contidos nas sondas. A distância abaixo e acima dos pontos de medida de $\mathrm{T}_{u}$ e $\mathrm{T}_{\mathrm{d}}$ foi de $0,005 \mathrm{~m}$ para as sondas do tipo "Dynagage", modelo SGB 19. Os demais parâmetros da equação $(\mathrm{Q}, \mathrm{k}, \mathrm{A}, \mathrm{c}, \mathrm{K}$ e E) dependem das condições de operação elétrica das sondas e das características do caule e da seiva das plantas e encontramse descritos em Resultados e Discussão.

Os dados obtidos de fluxo de seiva $(\mathrm{F})$ foram convertidos por unidade de área foliar, isto é, em $\mathrm{g} \mathrm{h}^{-1} \mathrm{~m}^{-2}$, com base na área foliar total de cada planta. Esta conversão possibilitou a comparação e a caracterização do índice de estresse hídrico da planta (IEHP), que foi calculado com a equação descrita a seguir: IEHP $=1-\mathrm{F}_{\mathrm{ES}} / \mathrm{F}_{\mathrm{NE}}$ em que, $\mathrm{F}_{\mathrm{NE}}$ e $\mathrm{F}_{\mathrm{ES}}$ são as taxas de $\mathrm{F}$ obtidas sob as duas condições de regime hídrico estudadas, isto é, não 


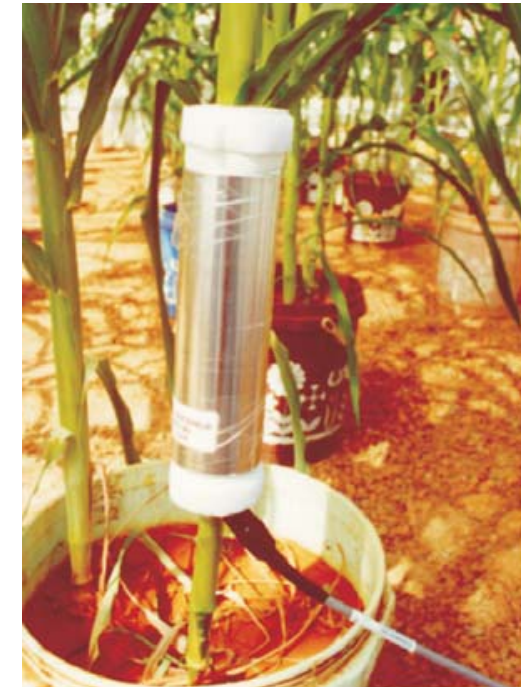

(a)

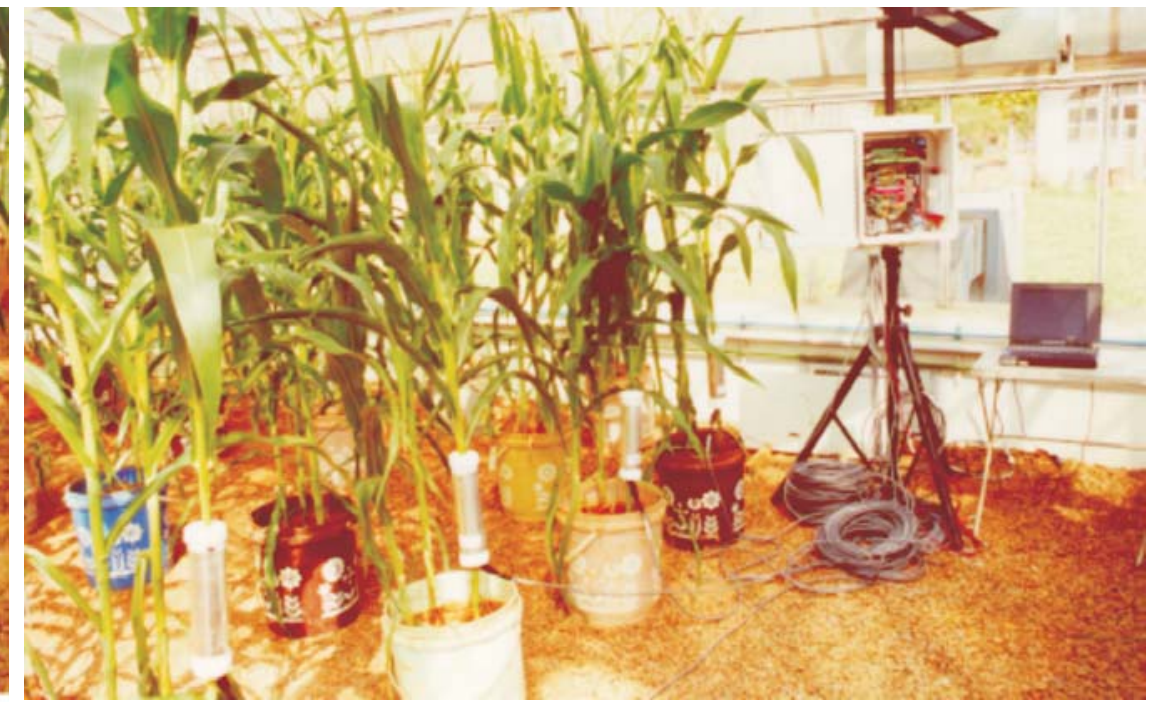

(b)

FIGURA 1. Sonda de balanço de energia (a) e sistema de medição automática de fluxo de seiva, instalado em segmentos de caules de duas linhagens de milho (b) (Embrapa Milho e Sorgo, Sete Lagoas, MG, 2001).

estressada (NE) e estressada (ES), respectivamente.

\section{Resultados e Discussão}

Os parâmetros Q, k, A, c, K e E da equação de fluxo de seiva (F) dependem das condições de operação elétrica das sondas e das características do caule e da seiva das plantas (Merva, 1996; Bavel et al., 1994). As sondas foram instaladas nos caules das plantas aos 58 DAS (início da fase de florescimento), ocasião que deu início à diferenciação das duas condições de regime hídrico, isto é, um não estressado (NE) e outro estressado (ES). Os segmentos dos caules das quatro plantas das linhagens L 1170 e L 13.1.2 apresentaram diâmetros de 1,53 a 1,75 cm e 1,68 a $1,75 \mathrm{~cm}$, a uma altura de $0,25 \mathrm{~m}$ acima do solo dentro dos vasos, respectivamente. Para se ter condições adequadas de operação elétrica das sondas, esses diâmetros de caule requerem voltagem de alimentação ou excitação das jaquetas térmicas da ordem de 4,5 Vdc (Bavel et al., 1994). Como as sondas apresentam resistência elétrica de 65 Ohms, a quantidade de calor Q suprida aos segmentos de caule foi de $0,315 \mathrm{~W}$. A constante $\mathrm{K}$ utilizada foi de $0,82 \mathrm{~W} \mathrm{mV}^{-1}$. A força eletromotriz $\mathrm{E}$ do elemento sensor de fluxo de calor preso ao segmento aquecido é o termo da equação que designa a fonte de energia elétrica necessária para produzir uma corrente elétrica I no circuito. $\mathrm{O}$ circuito das sondas utilizadas gerou uma força eletromotriz $\mathrm{E}$ de $4,5 \mathrm{~V}$ e produziu uma corrente elétrica I de 0,070 A.

$\mathrm{O}$ valor de condutividade térmica dos caules das linhagens de milho " $\mathrm{k}$ " foi de $0,54 \mathrm{Wm}^{-1}$ ${ }^{\circ} \mathrm{K}^{-1}$, tendo em vista tratar-se de plantas com características herbáceas. $\mathrm{O}$ valor de calor específico da seiva c foi de $4,18 \mathrm{~J} \mathrm{~g}^{-1}{ }^{\circ} \mathrm{C}^{-1}$, uma vez que a seiva é basicamente constituída por água, e os valores das áreas das seções transversais dos segmentos de caules aquecidos $\left(\mathrm{A}, \mathrm{em} \mathrm{m}^{2}\right.$ ) foram determinados a partir dos respectivos diâmetros transversais medidos.

Os valores de área foliar total foram obtidos aos 72 DAS (27/04/2001), durante o período de florescimento. Para o regime hídrico de

Revista Brasileira de Milho e Sorgo, v.4, n.3, p.344-354, 2005 
água no solo NE, as linhagens L 1170 e L 13.1.2 apresentaram valores de área foliar total de 0,3724 e $0,3456 \mathrm{~m}^{2}$ e de 0,2829 e $0,2596 \mathrm{~m}^{2}$, respectivamente. Para a condição hídrica ES, as linhagens L 1170 e L 13.1.2 forneceram valores de área foliar total de 0,3188 e $0,2920 \mathrm{~m}^{2}$ e de 0,2363 e $0,2130 \mathrm{~m}^{2}$, respectivamente. Os resultados indicam que a linhagem L 1170 apresentou maior área foliar total em relação à linhagem L 13.1.2. A condição hídrica ES reduziu a área foliar total em ambas as linhagens estudadas.

Os resultados da variação de fluxo de seiva (F) por unidade de área foliar das duas linhagens de milho (L 1170 e L 13.1.2), em função do tempo, para dois regimes hídricos de água no solo (NE e ES) e diferentes dias após a semeadura, são apresentados na Figura 2. Verifica-se que as sondas de balanço de energia mostraramse sensíveis para detectar variação de fluxo de seiva, ou seja, taxa de transpiração das plantas, e que, de modo geral, os maiores valores de fluxo de seiva ocorreram entre as $12 \mathrm{e}$ as 15 horas, indicando maior demanda evaporativa da atmosfera no interior da casa de vegetação nesse período.

Os resultados indicam que a linhagem $\mathrm{L}$ 1170 mostrou-se mais sensível ou menos tolerante ao estresse hídrico, quando comparada com a linhagem L 13.1.2, uma vez que foram verificados valores menores de fluxo de seiva para as duas condições de regime hídrico estudadas (NE e ES). Essa característica da linhagem L 1170 foi mais evidenciada na condição de estresse hídrico.

Um dos mecanismos de tolerância à deficiência hídrica (Hale \& Orcutt, 1987), importante na taxa de requerimento de água das plantas (fluxo de seiva) e na captação de energia luminosa usada na fotossíntese, processos pelos quais as plantas produzem grande parte das substâncias necessárias ao seu crescimento e desen- volvimento, é a área foliar. Uma redução de área foliar das plantas, além de causar diminuição do fluxo de seiva, acarreta redução na taxa de assimilação de $\mathrm{CO}_{2}$ ou fotossíntese. As plantas tendem a reduzir a sua área foliar para se ajustarem e se adaptarem a uma condição desfavorável de conteúdo de água no solo (ES).

A linhagem L 13.1.2, de menor área foliar total, foi a mais tolerante ao estresse hídrico, uma vez que, mesmo sob condições hídricas ES, apresentou bons valores de fluxo de seiva.

A Figura 3 mostra a variação do índice de estresse hídrico de plantas (IEHP) das duas linhagens de milho (L 1170 e L 13.1.2), em função do tempo para diferentes dias após a semeadura. Verifica-se que a linhagem L 1170 é a mais sensível ao estresse hídrico, uma vez que foram obtidos com maior frequência valores mais elevados de IEHP, da ordem de 0,4 a 0,8 . Já a linhagem L 13.1.2 apresentou valores bem menores de IEHP, sendo obtidas com maior freqüência variações de IEHP da ordem de $-0,2$ a 0,4 , comprovando tratar-se de uma linhagem mais tolerante à deficiência hídrica. Mesmo a linhagem $\mathrm{L}$ 13.1.2 chegou a apresentar valores mais elevados de IEHP, nos dias 17, 18, 19, 24 e 26 de abril de 2001, indicando, provavelmente, uma condição favorável para o estresse hídrico manifestarse nas plantas, isto é, alta demanda evaporativa da atmosfera e limitação de conteúdo de água no solo.

Alguns valores negativos obtidos de IEHP provavelmente estão relacionados a uma reposição inadequada de água de irrigação aos vasos, principalmente àqueles vasos mantidos sob regime hídrico não estressado (condição de taxa de T máxima ou potencial) e, também, a uma demanda evaporativa da atmosfera desuniforme no interior da casa-de-vegetação. Isso pode ocasionar valores de $\mathrm{T}_{\mathrm{ES}}$ (atual ou real) maiores que $\mathrm{T}_{\mathrm{NE}}$ 

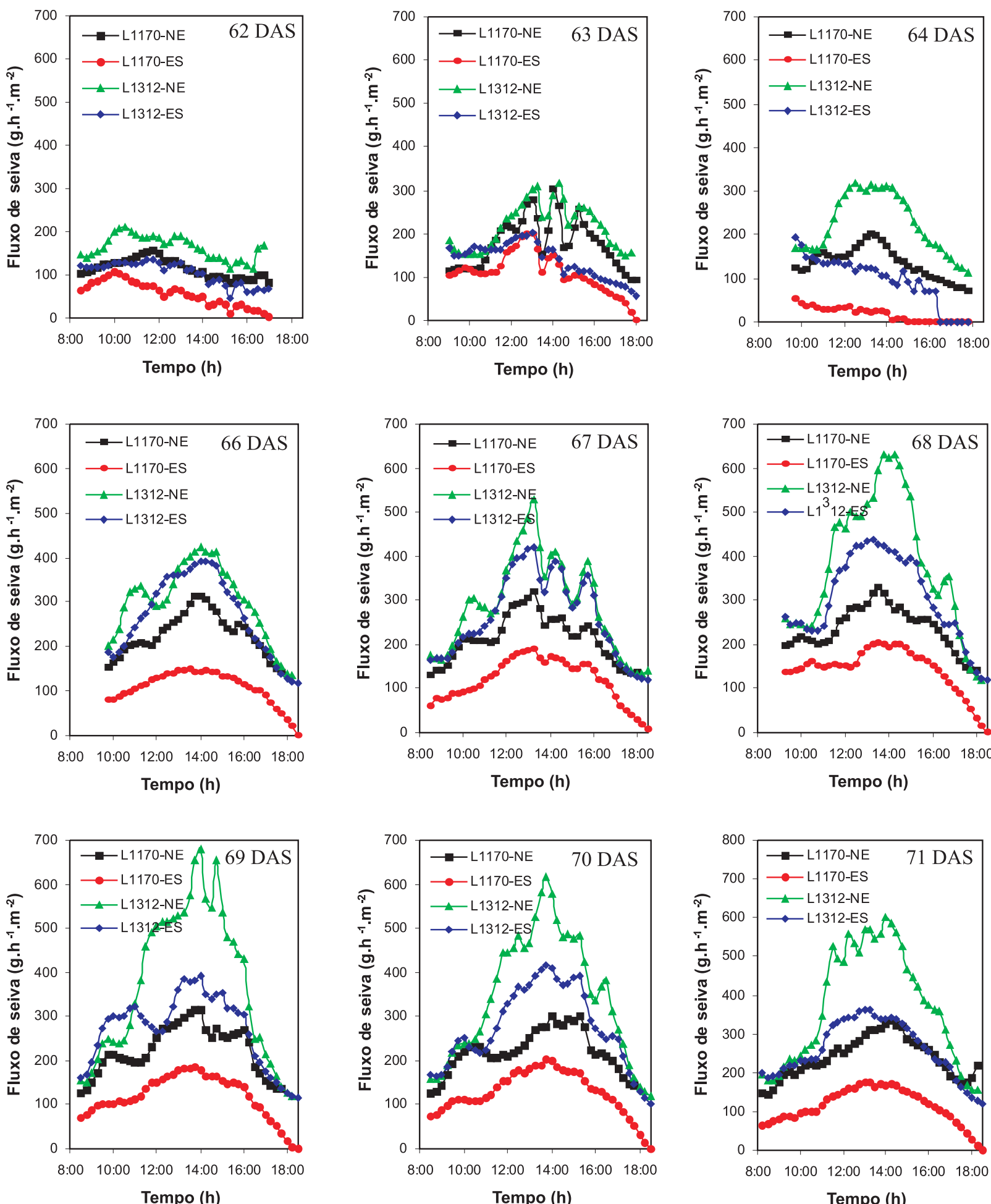

FIGURA 2. Variação de fluxo de seiva por unidade de área foliar $\left(\mathrm{g} \mathrm{h}^{-1} \mathrm{~m}^{-2}\right)$ de duas linhagens de milho (L 1170 e L 13.1.2), em função do tempo, para dois regimes hídricos de água no solo (não estressado-NE e estressado-ES) e diferentes dias após a semeadura (DAS).

Revista Brasileira de Milho e Sorgo, v.4, n.3, p.344-354, 2005 

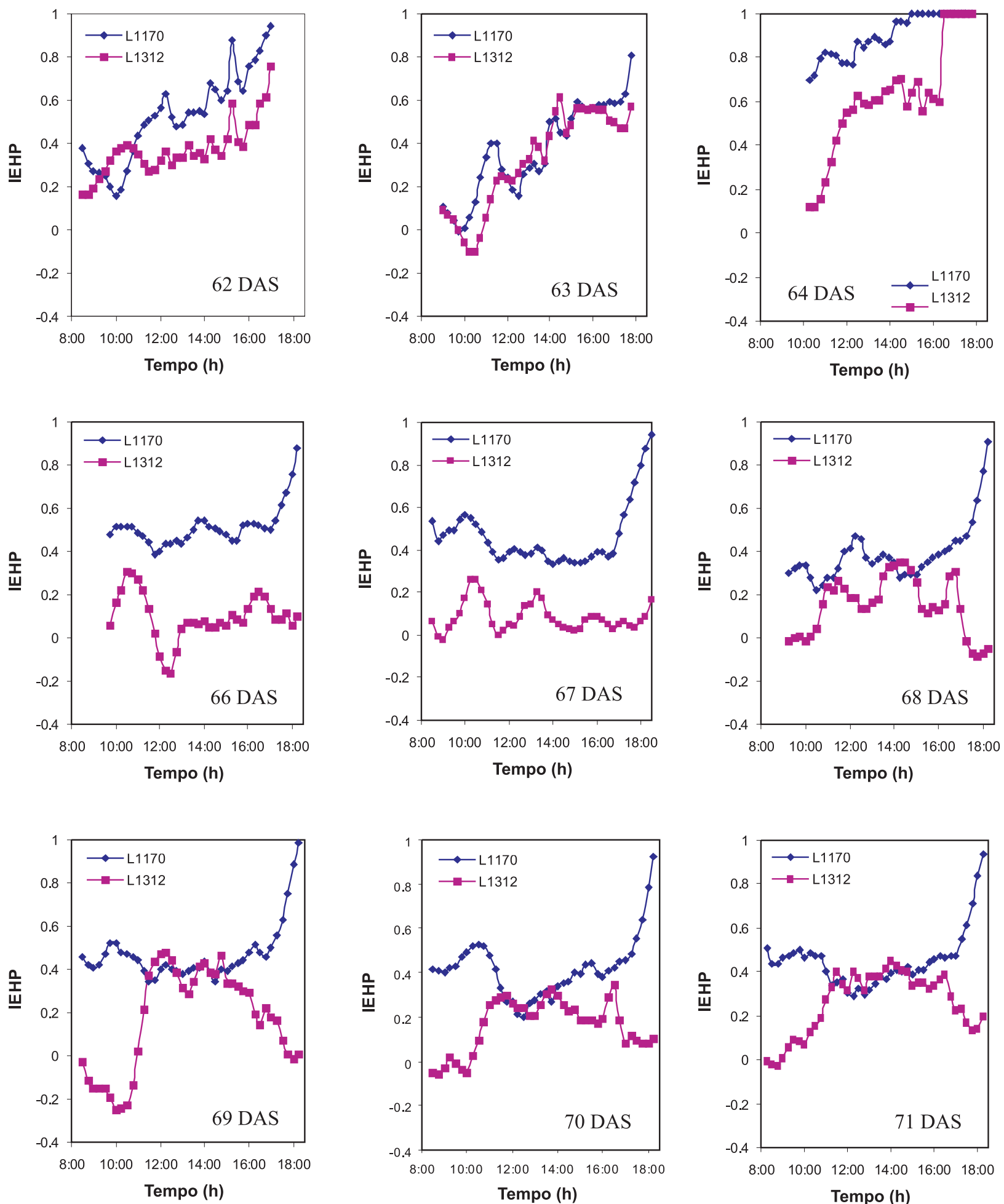

FIGURA 3. Variação de índice de estresse hídrico da planta (IEHP) de duas linhagens de milho (L 1170 e L 13.1.2). em função do tempo. para diferentes dias após a semeadura (DAS).

Revista Brasileira de Milho e Sorgo, v.4, n.3, p.344-354, 2005 
(máximo ou potencial). De um modo geral, os resultados indicam que a equação IEHP possibilitou boa caracterização de estresse hídrico das duas linhagens estudadas.

\section{Conclusões}

As sondas de fluxo de seiva instaladas nos caules das plantas mostraram-se sensíveis para detectar variação de fluxo de seiva e a equação IEHP mostrou-se uma metodologia adequada para a caracterização do estresse hídrico das duas linhagens de milho estudadas; a área foliar total das duas linhagens estudadas foi reduzida pela condição do estresse hídrico; a linhagem de milho L 1170 forneceu menores valores de fluxo de seiva e mostrou-se mais sensível ao estresse hídrico (maiores valores de IEHP); a linhagem de milho L 13.1.2 forneceu maiores valores de fluxo de seiva e mostrou-se mais tolerante ao estresse hídrico (menores valores de IEHP).

\section{Agradecimentos}

À Embrapa e ao programa PRODETAB pelo financiamento desta pesquisa, por meio dos projetos Embrapa 12.1999.021-02 e PRODETAB 161-2/1998

\section{Literatura Citada}

BAVEL, M. G. van; BAVEL, C. H. M. van; LUDWIG, K.; HARRELSON, D. THANNOON, S. Flow $\mathbf{3 2}^{\mathrm{tm}}$ installation and operation manual, version 2.12 software. Houston: Dynamax, 1994. 178 p.

CERMAK, J., KUCERA, J.; PENKA, M. Improvement of a method of sap flow determination in fully-grown trees based on heat balance with direct electrical heating of xylem. Biologia Plantarum, Prague, v. 18, p. 99-105, 1976.
COHEN, Y.; FUCHS, M.; GREEN, G. C. Improvement of the heat pulse method for determining sap flow in trees. Plant, Cell and Environment, Oxford, v. 4, p. 391-397, 1981.

DURÃES, F. O. M.; MAGALHÃES, P. C.; OLIVEIRA, A. C.; SANTOS, M. X. dos; GAMA, E. E. G.; GUIMARÃES, C. T. Combining ability of tropical maize inbred lines under drought stress conditions. Crop Breeding and Applied Biotechnology, Londrina, v. 2, n. 2, p. 291-298, 2002.

EDWARDS, W. R. N.; WARWICK, N. W. M. Transpiration from a kiwifruit vine as estimated by the heat pulse technique and the PenmanMonteith equation. New Zealand Journal of Agricultural Research, Wellington, v. 27, p. 537-543, 1984.

GOMIDE, R. L.; JORDAN, K. A.; SLACK, D. C. A transient heat probe sensor for measuring transpiration in woody plant stems. In: WORKSHOP ON REAL TIME SENSING AND CONTROL OF AUTOMATED IRRIGATION SYSTEMS, 16, 1992, Budapest. Proceedings... Budapest: ICID, 1992. p. 51-58.

HALE, M. G.; ORCUTT, D. M. The physiology of plants under stress. New York: J. Wiley, 1987. $206 \mathrm{p}$.

MERVA, G. E. Physical principles of the plant biosystem. St. Joseh: ASAE, 1996. 272 p.

PICKARD, W. F. A heat pulse method of measuring water flux in woody plant stems. Mathematical Biosciences, New York, v. 16, p. 247-262, 1973.

SAKURATANI, T. A heat balance method for measuring water flux in the stem of intact plants. Journal Agricultural Meteorology, Tokyo, v. 37, n. 1, p. 9-17, 1981. 
SAKURATANI, T. Two thermic methods for SAKURATANI, T. Improvement of the probe for measuring water flux in the stem of intact plants measuring water flow rate in intact plants with and their applications. Bulletin of the National the stem heat balance method. Journal Institute of Agricultural Sciences, series A, Agricultural Meteorology, Tokyo, v. 40, n. 3, p. Tokyo, v. 29, p. 47-121, 1982. 273-277, 1984. 